\title{
Effect of apexification on occlusal resistance of immature teeth
}

\author{
WooCheol Lee ${ }^{1}$ and Yeon-Jee Yoo ${ }^{2^{*}}$
}

\begin{abstract}
Background: Strain distribution was investigated to assess the occlusal resistance alterations in immature teeth under different occlusal force.

Methods: In vitro apexification models of teeth with a funnel-shaped immature apex were obturated with mineral trioxide aggregate (MTA; ProRoot MTA) using different combinations of core materials (10/group): group 1, full-length orthograde obturation of MTA; group 2, a 5-mm MTA apical plug with a composite core; group 3, a 5-mm MTA apical plug and back-filling with warm gutta-percha. Teeth with calcium hydroxide (CH)-medicated canals and untreated teeth with normal apices were tested as controls. The teeth were arranged between two adjacent normal-apex teeth, embedded in a resin mold with a simulated periodontal ligament space. Strain data were recorded from the 3-unit teeth assembly under static compressive occlusal forces (50,100, 200, and 300 N). Measurements were repeated 20 times for each condition, and the data were statistically analyzed.
\end{abstract}

Results: The immature teeth showed altered occlusal force resistance, placing increased strain on adjacent teeth. Teeth with $\mathrm{CH}$-medicated canals showed significantly inferior occlusal resistance under all tested forces $(P<0.05)$. Application of an MTA plug with deep composite resin core resulted in significantly better stress-bearing capacity especially under forces of 50 and $300 \mathrm{~N}(P<0.05)$.

Conclusions: The pattern of occlusal force distribution in immature teeth differed according to the canal obturation materials used for apexification. Immature teeth with an MTA apical plug showed more favorable occlusal force resistance than those with $\mathrm{CH}$-medicated canals.

Keywords: Apexification, Immature tooth, Occlusal resistance, Strain gauge

\section{Background}

Regenerative endodontic procedures enable continued root growth, in both length and width, in immature teeth with pulp necrosis and apical periodontitis. However, it is not always possible to achieve successful root maturation. In particular, immature teeth with completely destroyed apical papillae or previous unsuccessful endodontic interventions fail to complete further root formation. An

\footnotetext{
*Correspondence: dusw132@snu.ac.kr

${ }^{2}$ Department of Comprehensive Treatment Center, Seoul National University Dental Hospital, Daehakro 101, Jongno-Gu, Seoul 03080, Republic of Korea

Full list of author information is available at the end of the article
}

alternative treatment strategy in such cases is to induce apical barrier formation by apexification.

Concerns exist regarding the use of calcium hydroxide $(\mathrm{CH})$ or mineral trioxide aggregate (MTA) as an intracanal medicament in apexification treatment, since these patients are usually relatively young. The conventional approach induces the formation of an apical barrier through long-term $\mathrm{CH}$ treatment $[1,2]$. This treatment strategy involves multiple visits for medication changes and root canal irrigation over a prolonged period, which may lead to the loss of temporary dressings and re-infection. During the follow-up period, the high $\mathrm{pH}$ of the materials may weaken the dentin [3], making the tooth prone to failure [3-6]. Furthermore, cervical root 
fracture is a frequently-observed adverse event during apexification treatment and follow-up [5-7]. For this reason, several researchers have investigated possible methods of strengthening the tooth sufficiently to withstand the treatment period while maintaining proper function. In this regard, the use of MTA was advocated because of its proven favorable biological and sealing effects [8]. A general consensus exists regarding the use of MTA in regenerative endodontic procedures, especially for single-visit apexification, in which nonsurgical compaction of MTA into the apical end of the root canal can create an artificial apical stop and enable immediate obturation of the root canal [9].

Root reinforcement is a priority in the treatment of immature permanent teeth. Each occluding tooth and its root transmit a different amount of stress to the supporting architecture depending on its occlusal contact area, crown and root, location in dental arch, and occlusal scheme. When a tooth is replaced by a substitute, such as an open-apex tooth, its adjacent teeth will experience a different distribution of occlusal forces during mastication. However, to our knowledge, no previous study has investigated occlusal force resistance in teeth with immature root architecture. Therefore, the present study was conducted to investigate the effects of the apexification method on strain distribution in immature teeth under different occlusal forces.

\section{Methods}

\section{In vitro apexification model}

The sample size was calculated with G*Power 3.1.9 (Universität Kiel, Kiel, Germany) to detect significant differences ( $\alpha=0.05,85 \%$ power). The estimated sample size was 10 teeth in each group. A total of 50 single-rooted extracted human lower premolars with similar crown and root dimensions were used in this study. Teeth with an intact crown and root that had not undergone any treatments were included. Teeth with cervical abrasions were excluded to minimize possible micro-flexion under loading. An in vitro apexification model was prepared according to a previous study [10]. The mean crown dimensions of the collected teeth were $8.2 \pm 0.7 \mathrm{~mm}$ in the maximum mesio-distal dimension and $9.5 \pm 0.8 \mathrm{~mm}$ in crown height measured from the cusp tip to the cementoenamel junction (CEJ) at the buccal aspect. The crown dimensions were standardized to a maximum mesio-distal dimension of $7.0 \mathrm{~mm}$ and a crown height of $8.0 \mathrm{~mm}$ from the CEJ. To standardize root length, we cut approximately $3 \mathrm{~mm}$ of the apical root tip, resulting in an 8.0-mm root length below the CEJ measured at the buccal surface.

The teeth were accessed with a round carbide bur \#4 (Komet, Rock Hill, SC), and their root canals were enlarged with a Gates Glidden bur \#5 (Mani,
Utsunomiya, Japan) to the working length. A simulated divergent open apex was generated by retrograde preparation with a tapered diamond bur (CR-11F, Mani, Utsunomiya, Japan). The root canals were irrigated with a $5.25 \%$ sodium hypochlorite $(\mathrm{NaOCl})$ solution between instrumentation, and immersed in a $17 \%$ ethylenediaminetetraacetic acid solution $(\mathrm{pH}$ 7.2) for $1 \mathrm{~min}$ before a final flush with $5.25 \% \mathrm{NaOCl}$ solution. All irrigants were activated using intracanal ultrasonic devices (P5 Newtron XS; Satelec Acteon group, Mérignac, France). Finally, the canals were copiously rinsed with sterile distilled saline and dried with sterile paper points.

The teeth were randomly assigned to the following experimental groups and obturated accordingly: group 1, full-length orthograde obturation of MTA (ProRoot MTA; Dentsply Tulsa Dental, Tulsa, OK); group 2, a 5-mm MTA apical plug with a composite core; and group 3, a 5-mm MTA apical plug and back-filling with warm gutta-percha (GP). MTA obturation was performed using the obturation technique suggested by Bogen and Kuttler [11]. ProRoot MTA was mixed with distilled water according to the manufacturer's instructions and placed incrementally with a carrier gun. An SS K-file with a \#100 size was used to compact the apical 3-4 mm, then progressively larger K-files were used for further compaction. The final coronal portion was tamped by using stainless steel hand pluggers to complete the root canal obturation. Proper placement and thickness were verified by radiographic examinations. Following obturation, the teeth were stored at $37{ }^{\circ} \mathrm{C}$ under $100 \%$ humidity for a week to allow complete setting of the filling materials. The access cavities were sealed using resin composite (Z250; 3 M ESPE, St Paul, MN) and bonding agent (Scotchbond multipurpose; $3 \mathrm{M}$ ESPE). Teeth with $\mathrm{CH}$ medicated canals (CleaniCal, Maruchi, Wonju, Korea) and untreated teeth with normal apices were tested as controls $\left(\mathrm{n}=10\right.$ each). Teeth were stored at $37^{\circ} \mathrm{C}$ with $100 \%$ humidity for 3 weeks until further analysis.

\section{Configuration of the instrument for strain measurement under occlusal forces}

The instrument for measuring strain development under occlusal forces consisted of a 3-unit teeth assembly constructed with extracted human teeth, strain gauges, and a data acquisition board (Fig. 1). Two intact teeth with normal apices (adjacent teeth) and the treated tooth (experimental tooth) were arranged in a straight line in a single occlusal plane and embedded in a mold. The roots were double-covered with $0.13-\mathrm{mm}$ paraffin film (Parafilm M; Sigma-Aldrich, St. Louis, MO) to simulate a periodontal ligament (PDL) space of approximately 0.25 $\mathrm{mm}$ thickness. Strain gauges (KFG-2-350-C1-11, Kyowa Electronic Instruments, Tokyo, Japan) were attached to 


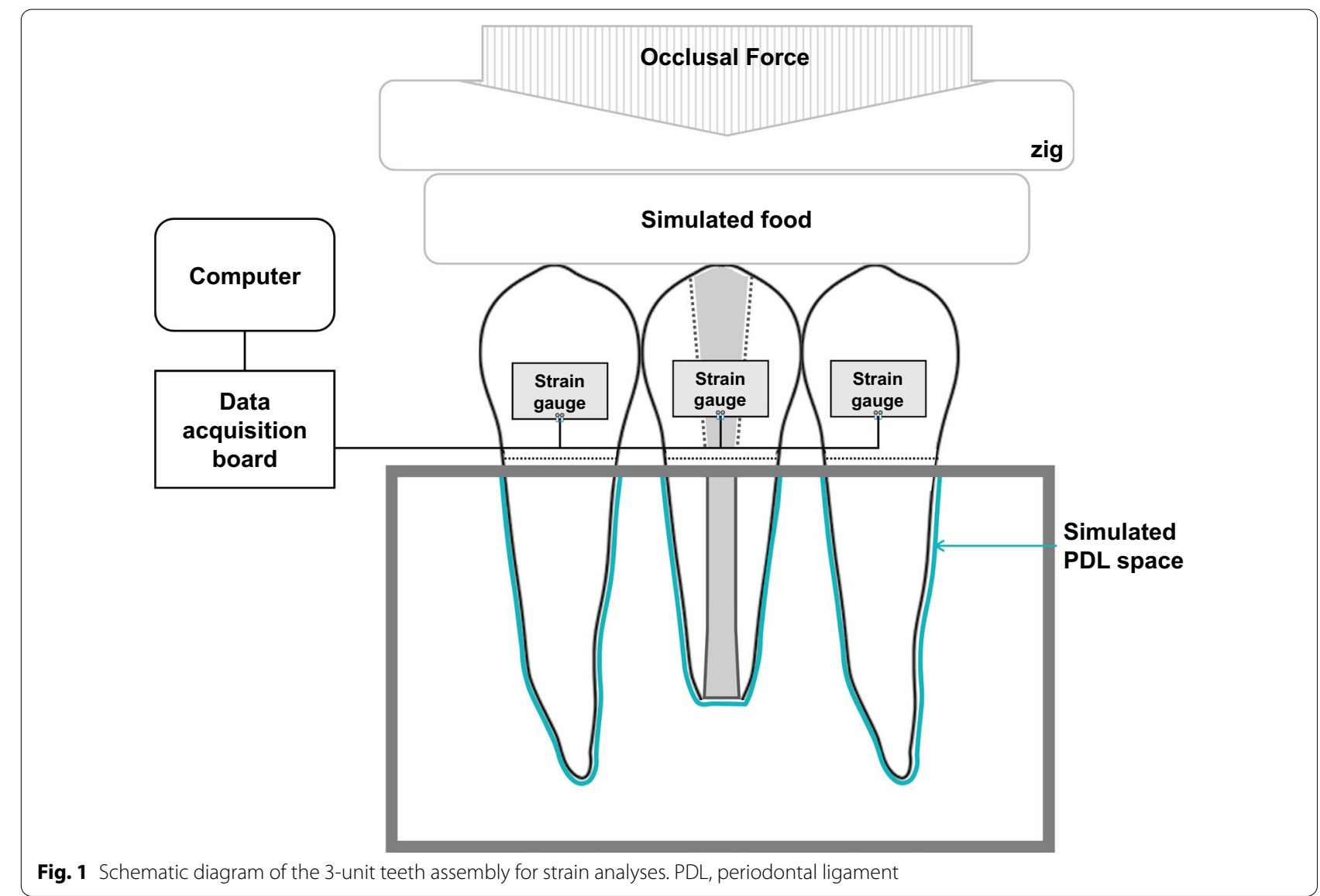

the buccal surfaces of the teeth at $4 \mathrm{~mm}$ below the buccal cusp tip. Simulated food fabricated with a polyvinylsiloxane impression material (Exafine putty type, GC Corp., Tokyo, Japan) was placed between the occlusal plane of the teeth and the test zig of the universal testing machine (Instron 8871, Instron Co., Norwood, MA) [12].

\section{Measurement of strain under occlusal force}

The 3-unit teeth assembly model was calibrated to ensure that it was free of residual strain under default conditions $(0 \mathrm{~N})$. Data from the untreated teeth with normal apices were used to confirm the even distribution of occlusal stress under tested forces. Compressive occlusal forces of $50,100,200$, and $300 \mathrm{~N}$ were applied with a universal testing machine, and strain values were simultaneously measured and recorded from each tooth. Strain measurements were repeated 20 times for each condition. The simultaneously recorded electronic measurements from each strain gauge were converted into occlusal force $(\mathrm{N})$ measurements for each tooth. The occlusal resistance of each tooth was calculated as the percentage (\%) of the occlusal force loaded in the treated tooth to the average occlusal force in the 3-teeth assembly, calculated from the summed values for all three strain gauges.

\section{Statistical analysis}

All analyses were performed using SPSS version 19 (IBM Corp., Armonk, NY, USA). Occlusal resistance data were pooled according to the apexification method and tested occlusal forces. All data were analyzed using two-way analysis of variance (ANOVA) with the type of apexification method and occlusal force as the main factors, followed by Tukey's post-hoc comparisons. For each tested occlusal force, data were separately analyzed with oneway ANOVA and Tukey's post-hoc comparisons. The significance level was set at $\alpha=0.05$.

\section{Results}

None of the tested teeth fractured during the experiment. Each summed occlusal force calculated from the three strain gauges was smaller than the applied occlusal forces, indicating stress absorption from tooth-supporting structures (e.g., simulated food, PDL, and mold) with a quadratic trendline $\left(R^{2}=0.95\right)$ in association with increasing occlusal force (Table 1).

All teeth in the simulated in vitro apexification model showed significantly lower occlusal resistance than the adjacent teeth with normal apex regardless of applied occlusal forces $(P<0.01)$. Teeth with $\mathrm{CH}$-medicated 
Table 1 Occlusal force loaded on the teeth and stress absorbed by other components of the 3-unit teeth assembly under different occlusal forces

\begin{tabular}{|c|c|c|c|c|}
\hline & \multicolumn{4}{|c|}{ Applied occlusal force (N) } \\
\hline & 50 & 100 & 200 & 300 \\
\hline Total occlusal force loaded on teeth (N) & $44.98 \pm 3.58$ & $81.20 \pm 5.83$ & $153.34 \pm 5.40$ & $185.85 \pm 17.01$ \\
\hline $\begin{array}{l}\text { Percentage (\%) of stress absorption from simulated food } \\
\text { and tooth-supporting structures }\end{array}$ & $10.04 \pm 7.16$ & $18.79 \pm 4.32$ & $23.32 \pm 5.70$ & $38.04 \pm 5.67$ \\
\hline
\end{tabular}

canals showed least occlusal resistance under all tested forces than teeth that underwent other treatments $(P<0.05)$. Two-way ANOVA suggested that both factors (apexification method and applied occlusal forces) and their interaction were significant $(P=0.000)$. Teeth with 5-mm MTA plugs with deep composite cores (group 2) showed significantly better stress bearing capacity under all tested forces than the other apexification models $(P<0.05)$. Under 50 - and $300-\mathrm{N}$ occlusal forces, the teeth in group 2 showed similar occlusal resistance to adjacent teeth with normal apices $(P>0.05)$. The full-length MTAfilled roots showed significantly lower occlusal resistance under forces of 50- and 200-N than the other two groups that had been backfilled with either GP or composite resin. The occlusal resistances (\%) of immature teeth treated with different apexification methods under each different occlusal force are presented in Fig. 2.

\section{Discussion}

To date, no study has comprehensively determined changes in occlusal resistance in immature teeth, although some studies have estimated the strength of immature teeth, typically using ultimate fracture strength [13-16]. Load-to-failure testing is a simple way to estimate the ultimate strength of a specimen, but the test setting (e.g., cross-head speed or load angle) varies widely, and testing assemblies exclude the physiological environment (such as PDL space). Finite element analysis is another approach to stress analysis that uses 2- or 3-dimensional computer simulated models. This

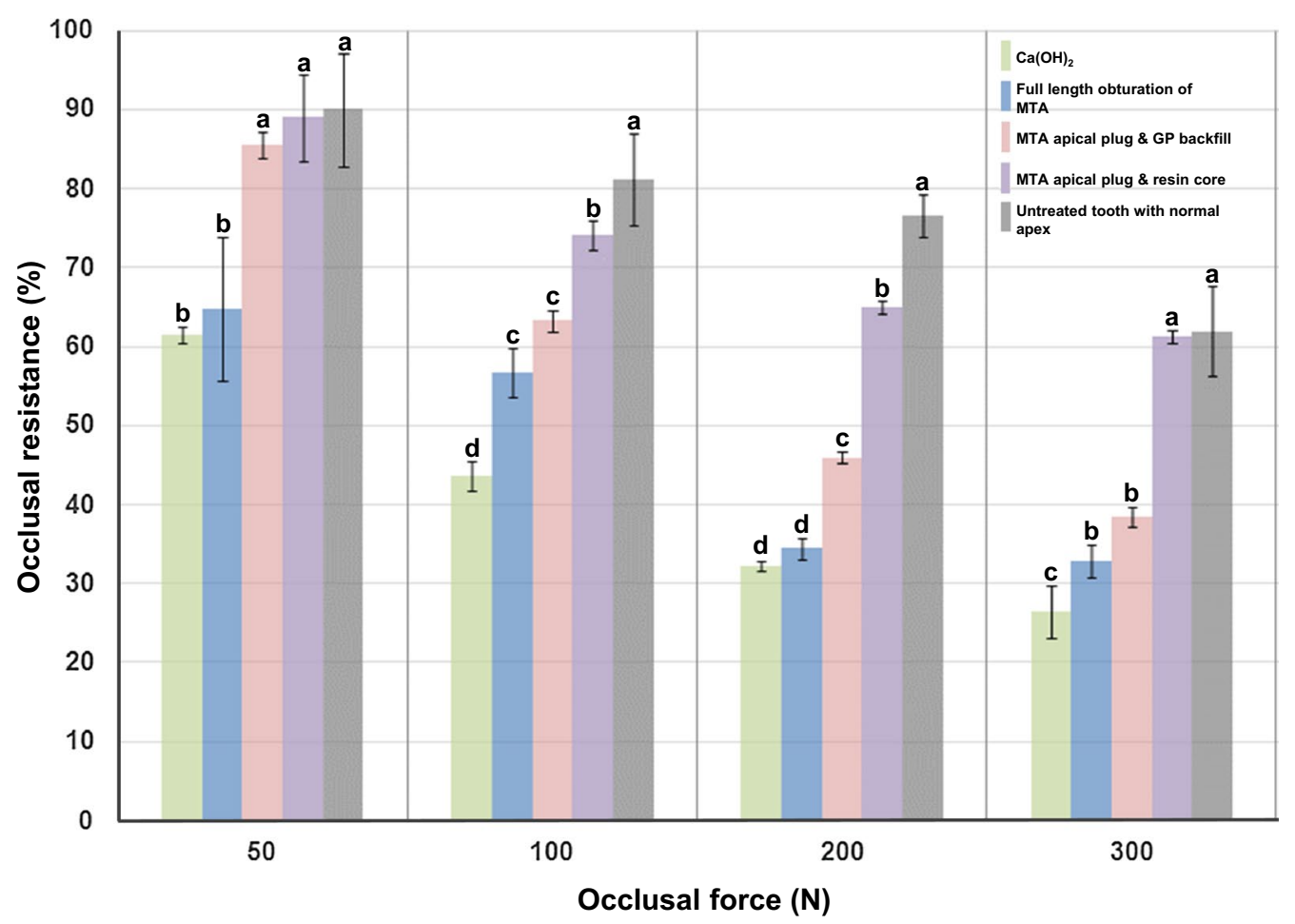

Fig. 2 Occlusal resistance (\%) of immature teeth treated with different apexification methods. MTA, mineral trioxide aggregate; GP, gutta-percha 
approach is useful for understanding stress distribution within a simulated graphic model, but interpretation of the results can be difficult because this method assumes that the tooth structure is an isotropic and homogeneous material. The results differ according to the type of pre-set model (e.g., linear or nonlinear, plastic or elastic). These methods cannot represent occlusal force distribution and resistance in clinical settings; hence, they have limited relevance in predicting the clinical performance of immature teeth.

In this study, we used human teeth with strain gauges attached to measure the actual stress that they experienced under occlusal forces on an immature tooth during and after apexification. The tested tooth was aligned in a 3-unit teeth assembly simulating adjacent teeth and the PDL space as a stress breaker. It has been reported that the average chewing force varies from 11 to $150 \mathrm{~N}$, whereas the force peaks are $200 \mathrm{~N}$ in the anterior area, $350 \mathrm{~N}$ in the posterior area, and $1000 \mathrm{~N}$ in patients with bruxism [17]. In another study, the maximum bite forces exhibited by adults in the molar area ranged from 250 to $400 \mathrm{~N}$, and forces in the anterior area ranged from 140 to $170 \mathrm{~N}$ [18]. Therefore, we preset the occlusal forces as 50 to $300 \mathrm{~N}$.

All simulated immature teeth showed significantly less strain under all tested occlusal forces, and the $\mathrm{CH}$ medicated canals showed the lowest values among the tested teeth. The inferior occlusal resistance of $\mathrm{CH}$-filled teeth may be due to the absence of an apical plug to resist compressive forces. $\mathrm{CH}$ in a non-set, aqueous suspension is recommended as the material of choice for apexification $[1,2]$. Despite the unpredictability of apical closure, intracanal $\mathrm{CH}$ medication can prevent the ingress of granulation tissue into the root canal and inhibit periapical osteoclastic activity $[1,2]$. Occlusal force resistance might have different patterns if an apical calcified barrier is formed, but it was not possible to simulate an irregular porous apical barrier in the in vitro setup.

MTA-filled immature teeth with full-length roots also transmitted occlusal stress to the adjacent teeth. Owing to the slow hydration rate of dicalcium silicate, which is one of the main components of MTA, occlusal force measurements were performed 3 weeks after specimen preparation to maximize the compressive strength of the material [19]. MTA is known to form a superficial apatite layer and induce intratubular mineralization that are supposed to enhance sealability of the material [20-25]. However, the firmly set material with its micromechanical retentive form in the root dentin was not directly connected to improved resistance to compressive occlusal forces. This might have been because the MTA surface acted as a stress endpoint, transmitting the strain to the adjacent canal wall. If the material surface ends at the cervical area where the enamel ends and the force accumulates, the tooth will not be able to resist the occlusal stress.

For this reason, GP and a composite restoration were placed as reinforcement materials at the cervical area of the immature teeth. The GP backfill added more interfaces inside the canal, and failed to reinforce the thin canal wall. However, a deep composite restoration extending from the MTA plug surface to the occlusal top provided improved occlusal force resistance, which was comparable to that of normal mature teeth. The results of $\mathrm{CH}$-medicated roots could be interpreted as showing that the internal interface at the cervical area adversely affects the occlusal force resistance of immature teeth.

Considering the importance of the periodontium in supporting teeth during function, the depleted occlusal force resistance of immature teeth during a prolonged treatment period might result in stress shielding of the periapical area of the treated tooth, thereby potentially slowing the healing of periapical inflammation and remodeling process of the alveolar bone proper [26-28]. It was also reported that the reduction of occlusal force altered the development and maintenance of mechanoreceptors such as Ruffini endings in the PDL [29-31].

A limitation of the current experiment is that only compressive forces were simulated. When a tensile force is loaded, we speculate that the situation will be more complex. Considering the compressive yield strength of dental tissues, strain development under compressive occlusal forces would not be significant enough to cause immediate tooth failure [32]. However, when a lateral force is applied, higher tensile stress will be generated than when a compressive load is applied to the same area. Given the thin root wall of immature teeth, such tensile overloading may cause cracks or even root fracture. Therefore, proper adjustments of occlusal surfaces should be performed to prevent these events.

Within the limitations of this study, it was confirmed that the pattern of occlusal force distribution in immature tooth differed according to the canal obturation material used for apexification. Application of an MTA plug with a deep composite resin core could increase the occlusal force resistance of immature teeth during and/ or after apexification treatment. Further in-depth studies are required to optimize apexification procedures in terms of clinical performance during the treatment period.

\section{Conclusions}

Under the conditions of this in vitro study, it was concluded that: 
1 Occlusal force distribution varied in immature teeth depending on the root canal obturation material used for apexification.

2 Application of an MTA plug with a deep composite resin core could increase the occlusal force resistance of immature teeth during and/or after apexification treatment.

\section{Abbreviations}

CEJ: Cemento-enamel junction; CH: Calcium hydroxide; GP: Gutta-percha; MTA: Mineral trioxide aggregate; PDL: Periodontal ligament.

\section{Acknowledgements}

Not applicable.

\section{Authors' contributions}

LW; Study conception and design, Acquisition of data, Analysis and interpretation of data, Drafting of manuscript. YJY; Study design, Acquisition of data, Analysis and interpretation of data, Drafting and revision of manuscript. Both authors read and approved the final manuscript.

\section{Funding}

This study was financially supported by the Ministry for Health, Welfare \& Family Affairs through the Korea Healthcare Technology R\&D Project (A120815).

\section{Availability of data and materials}

All data used and/or analyzed during this research are available from the corresponding author on reasonable request.

\section{Ethics approval and consent to participate}

The present protocol was approved by Institutional Review Board of Seoul National University (CRI15015). The consent of the participants for the use of their extracted teeth was waived by IRB committee because the teeth were collected anonymously as part of a regular dental treatment and were not used for genetic testing or any other tests except for current experiment.

\section{Consent for publication}

For this type of study, formal consent is not required.

\section{Competing interests}

The authors declare that they have no competing interest.

\section{Author details}

${ }^{1}$ Department of Conservative Dentistry, Dental Research Institute, Seoul National University School of Dentistry, Seoul, Republic of Korea. ${ }^{2}$ Department of Comprehensive Treatment Center, Seoul National University Dental Hospital, Daehakro 101, Jongno-Gu, Seoul 03080, Republic of Korea.

Received: 29 May 2020 Accepted: 5 November 2020

Published online: 12 November 2020

\section{References}

1. Sheehy EC, Roberts GJ. Use of calcium hydroxide for apical barrier formation and healing in non-vital immature permanent teeth: a review. Brit Dent J. 1997;183:241-6.

2. Rafter M. Apexification: a review. Dental Traumatol. 2005;21:1-8.

3. White JD, Lacefield WR, Chavers LS, Eleazer PD. The effect of three commonly used endodontic materials on the strength and hardness of root dentin. J Endod. 2002;28:828-30.

4. Cvek M. Prognosis of luxated non-vital maxillary incisors treated with calcium hydroxide and filled with gutta-percha. A retrospective clinical study. Endod Dent Traumatol. 1992;8:45-55.
5. Hatibovic-Kofman S, Raimundo L, Zheng L, Chong L, Friedman M, Andreasen JO. Fracture resistance and histological findings of immature teeth treated with mineral trioxide aggregate. Dent Traumatol. 2008;24:272-6.

6. Andreasen JO, Farik B, Munksgaard EC. Long-term calcium hydroxide as a root canal dressing may increase risk of root fracture. Dent Traumatol. 2002;18:134-7.

7. Carvalho CA, Valera MC, Oliveira LD, Camargo CH. Structural resistance in immature teeth using root reinforcements in vitro. Dent Traumatol. 2005;21:155-9.

8. Parirokh M, Torabinejad M. Mineral trioxide aggregate: a comprehensive literature review-part III: clinical applications, drawbacks, and mechanism of action. J Endod. 2010a;36:400-13.

9. Morse DR, O'Larnic J, Yesilsoy C. Apexification: review of the literature. Quintessence Int. 1990;21:589-98.

10. Hong ST, Bae KS, Baek SH, Kum KY, Lee W. Microleakage of accelerated mineral trioxide aggregate and Portland cement in an in vitro apexification model. J Endod. 2008;34:56-8.

11. Bogen G, Kuttler S. Mineral trioxide aggregate obturation: a review and case series. J Endod. 2009;35:777-90.

12. Cho YE, Park EJ, Koak JY, Kim SK, Heo SJ, Park JM. Strain gauge analysis of occlusal forces on implant prostheses at various occlusal heights. Int J Oral Maxillofac Implants. 2014;29:1034-41.

13. Elnaghy AM, Elsaka SE. Fracture resistance of simulated immature teeth filled with Biodentine and white mineral trioxide aggregate - an invitro study. Dent Traumatol. 2016;32:116-20.

14. Karapinar-Kazandag M, Basrani B, Yamagishi VTK, Azarpazhooh A, Friedman S. Fracture resistance of simulated immature tooth roots reinforced with MTA or restorative materials. Dent Traumatol. 2016;32:146-52.

15. Sivieri-Araujo G, Tanomaru-Filho M, Guerreiro-Tanomaru JM, Bortoluzzi EA, Jorge EG, Reis JM. Fracture resistance of simulated immature teeth after different intra-radicular treatments. Braz Dent J. 2015;26:211-5.

16. Brito-Junior M, Pereira RD, Verissimo C, Soares CJ, Faria-e-Silva AL, Camilo $\mathrm{CC}$, et al. Fracture resistance and stress distribution of simulated immature teeth after apexification with mineral trioxide aggregate. Int Endod J. 2014;47:958-66.

17. Rezaei SM, Heidarifar H, Arezodar FF, Azary A, Mokhtarykhoee S. Influence of connector width on the stress distribution of posterior bridges under loading. J Dent (Tehran). 2011;8:67-74.

18. Fontijn-Tekamp FA, Slagter AP, Van Der Bilt A, Van THMA, Witter DJ, Kalk W, et al. Biting and chewing in overdentures, full dentures, and natural dentitions. J Dent Res. 2000;79:1519-24.

19. Parirokh M, Torabinejad M. Mineral trioxide aggregate: a comprehensive literature review-part l: chemical, physical, and antibacterial properties. J Endod. 2010b;36:16-27.

20. Tay FR, Pashley DH, Rueggeberg FA, Loushine RJ, Weller RN. Calcium phosphate phase transformation produced by the interaction of the portland cement component of white mineral trioxide aggregate with a phosphate-containing fluid. J Endod. 2007;33:1347-51.

21. Han L, Okiji T, Okawa S. Morphological and chemical analysis of different precipitates on mineral trioxide aggregate immersed in different fluids. Dent Mater J. 2010;29:512-7.

22. Reyes-Carmona JF, Felippe MS, Felippe WT. Biomineralization ability and interaction of mineral trioxide aggregate and white portland cement with dentin in a phosphate-containing fluid. J Endod. 2009:35:731-6.

23. Gandolfi MG, Taddei P, Tinti A, Prati C. Apatite-forming ability (bioactivity) of ProRoot MTA. Int Endod J. 2010;43:917-29.

24. Bird DC, Komabayashi T, Guo L, Opperman LA, Spears R. In vitro evaluation of dentinal tubule penetration and biomineralization ability of a new root-end filling material. J Endod. 2012;38:1093-6.

25. Yoo YJ, Baek SH, Kum KY, Shon WJ, Woo KM, Lee W. Dynamic intratubular biomineralization following root canal obturation with pozzolan-based mineral trioxide aggregate sealer cement. Scanning. 2016;38:50-6.

26. Huiskes R, Ruimerman R, van Lenthe GH, Janssen JD. Effects of mechanical forces on maintenance and adaptation of form in trabecular bone. Nature. 2000:405:704-6.

27. Kerner J, Huiskes R, van Lenthe GH, Weinans H, van Rietbergen B, Engh $\mathrm{CA}$, et al. Correlation between pre-operative periprosthetic bone density and post-operative bone loss in THA can be explained by strain-adaptive remodelling. J Biomech. 1999;32:695-703. 
28. Brown IW, Ring PA. Osteolytic changes in the upper femoral shaft following porous-coated hip replacement. J Bone Joint Surg. 1985;67:218-21.

29. Hayashi S, Nakakura-Ohshima K, Ohshima H, Noda T, Honma S, Wakisaka $\mathrm{S}$, et al. The development of terminal Schwann cells associated with periodontal Ruffini endings in the rat incisor ligament. Brain Res. 2000;858:167-71.

30. Shi L, Atsumi Y, Kodama Y, Honma S, Wakisaka S. Requirement of proper occlusal force for morphological maturation of neural components of periodontal Ruffini endings of the rat incisor. Arch Oral Biol. 2006:51:681-8.
31. Shi L, Kodama Y, Atsumi Y, Honma S, Wakisaka S. Requirement of occlusal force for maintenance of the terminal morphology of the periodontal Ruffini endings. Arch Histol Cytol. 2005;68:289-99.

32. Craig RG, Johnson DW, Peyton FA. compressive properties of enamel, dental cements, and gold. J Dent Res. 1961;40:936-45.

\section{Publisher's Note}

Springer Nature remains neutral with regard to jurisdictional claims in published maps and institutional affiliations.
Ready to submit your research? Choose BMC and benefit from:

- fast, convenient online submission

- thorough peer review by experienced researchers in your field

- rapid publication on acceptance

- support for research data, including large and complex data types

- gold Open Access which fosters wider collaboration and increased citations

- maximum visibility for your research: over $100 \mathrm{M}$ website views per year

At BMC, research is always in progress.

Learn more biomedcentral.com/submissions 